\title{
Editorial note: Learning management systems and big data technologies for higher education
}

\author{
Shah J. Miah ${ }^{1} \cdot$ Muhammed Miah ${ }^{2}$. Jun Shen ${ }^{3}$ \\ Published online: 4 February 2020 \\ (C) Springer Science+Business Media, LLC, part of Springer Nature 2020
}

\section{Motivation}

We are living in a "data-driven era" where new data is continuously being generated by people, businesses, organisations, communities and society each and every moment. This rapidly growing and huge amount of data must be managed through effective way for producing useful information and human decision support for current and future problems solving, planning and practices improvements as well as to generate new knowledge for future generation. As a result, organizations globally are making significant investments to explore how to better utilise the huge data and its diversification to create value and actionable insights (for example, Pardos 2017; Miah et al. 2017, 2019a, b). Big data has been a popular research problem across different academic disciplines. Although this problem has been treated mainly for advancing and innovating technological development (Wang et al. 2017), organisations and business communities are continuously exploring different aspects, perspectives and contextual specifics to find or explore benefits and value adding for improving practices. A lot of existing studies have defined the big data considering large volumes of broadly varied and complexity of datasets that are continuously being generated. The consideration for defining this goes to velocity, volume, value, variety, and veracity, so-called the "five V's of Big Data" (Gandomi and Haider 2015). Organizations such as education institutes have started to treat the issues of big data for reinforcing traditional electronic learning and teaching methods and other relevant products, and services (McAfee et al. 2012). For doing this, opportunity of adopting latest analytics, predictive algorithms and other disruptive technologies are rapidly developed for advancing the traditional e-learning approaches, for example in improving learning management systems (LMS).

Shah J. Miah

shah.miah@vu.edu.au

1 VU Business School, Victoria University, Melbourne, Australia

2 Department of Business Information Systems, Tennessee State University, Nashville, TN, USA

3 School of Computing and Information Technology, University of Wollongong, Wollongong, NSW, Australia 
The opportunities arising from the big data and relevant research for education institutes recently enable disruptive change for organisations and human decision markers (Baesens et al. 2016). However, clarity is still at its embryonic stage specifically for what benefits organizations may recognize or find as their value adding, what and how different disruptive technologies can offer better practices such as for greater measures, flexibility, and economic and business sustainability. Previous research have been explored to identify various issues of big data within the education sector. For instance, research importance have been identified for social value and social wellbeing in education (Cech 2013), and public safety and security (Newell and Marabelli 2014). Increasing demands of relevant knowledge and skills in relation to managing big data are also realised by government bodies, for instance, using big data to, "enhance transparency, increase citizen engagement in public affairs, by private organisations, for processing big data for profit maximisation and customer satisfaction and retention analysis" (Tenney and Sieber, 2016).

Evolving technologies, together with the rapidly increasing complexity of big data (whether they are generated from internal and external sources) have created an obvious impact to our society and community. Therefore, it is an standing out demand for allowing advanced education and relevant process improvement. Emerging analytics technologies have also pushed higher education institutes for better utilisation of big data and its further meaningful processing. These technological tools cannot only be significantly enriching the learning experience in any disciplines, but also could assist improving learning practices or meeting any learning needs (Miah et al. 2020; Singh and Miah 2019) using modern design-based research approaches (Miah et al. 2008; Miah and Genemo 2016; Genemo et al. 2016; Miah et al. 2019) that have roots in the information systems research. In fact, the big data would have a significant impact on how the learning process may be transformed through using and adopting pedagogical and relevant technology-oriented knowledge.

\section{Aim and contributions}

The aim of this special issue was to bring together studies related to the use of emerging analytics and related assistive technologies in improving LMS and other relevant process \& practices in higher education. We called for empirical and theoretical studies to illustrate what, how and why modern emerging technologies are applied and enabled relevant debates to improve learning management strategies and systems. We have accomplished the task by conducting an effective process of scrutinising, reviewing, revising and electing appropriate studies for the special issue to be published. Proposed contribution of the special issue has twofold. First, we identified modern education technologies for improving learning delivery and how education institutes may improve their value adding utilising big data. Second, we acknowledged the specific education needs and learning curriculum development for meeting the emerging demands of big data within the higher education sectors, promoting the influence of how organizations and academic researchers may have a better realization of value adding from big data in practice.

First, studies of big data reinforce development of modern education technologies. The technologies are/will be used for improving learning tools that have been a rapidly evolving 
topic area and will be in future. For example, Bocevska et al. (2018) defined a personalized learning method as a part of LMS improvement that refers to a variety of learning experiences, approaches and strategies for addressing various learning needs, aspirations, interest and backgrounds of individual learners, through the use of data generated by the learners' activities. Whereas Zanjani et al. (2017) investigated the LMS design determinants that impact user engagement with LMS tools in higher education. Valsamidis et al. (2012) also investigated the design of LMS for improving provisions through data mining techniques and therefore proposed specific metrics for the assessment of the courses. These works are focused on the technological improvement rather than exploring on organisational and social implications and relevance into their studies. Stern and Willits (2011) proposed social media elements, specifically for enhancing collaboration and interaction in LMS design. However, Emelyanova and Voronina (2014) argued that design of LMS can be a challenging task as the relevant technologies are still growing that may better facilitate effective platform of virtual learning and therefore enhancing students' commitment and engagement as well as for the improvement of organisational learning outcomes in classroom settings.

Second, modern businesses and industries regularly practice and use data-driven strategies (Miah et al. 2020). It is important for investigating how new technologies may help to improve higher education uptake for producing graduates with relevant knowledge and skills. Current technology-oriented education remains largely limited to producing graduates with advanced big data knowledge and support service skills. Although some institutions have also focused on technology training for graduates' inhouse skills development on business technologies, where data science or data analytics have not traditionally been a major component in their programs and how current teaching might be improved by incorporating data-oriented knowledge with other soft transferable skills (Asamoah et al. 2017). Going through the key attributes of technological and pedagogical development for delivering and designing effective learning tools, we elected seven articles out of the twenty plus initial submissions that were having relevant topic areas within the aforementioned background.

\section{Outcome}

In "Measurement of e-services Quality: An Empirical Study of University of Bahrain" the authors described a measurement of the e-services quality and its impact on student e-satisfaction. This study proposed a research model that was evaluated through a quantitative investigation. The results showed that all of the dimensions of e-services quality have had an impact on student satisfaction for ease of use. The contribution of this article related to various relevant factors and how they affect to e-service quality adopted to measure the e-services at a university. The paper additionally provided recommendations for using the quality dimensions through websites, and some suggestions for future research that may add value for improving educational practices.

Next the article titled "Convergent approach to synthesis of the information learning environment for higher education" considered tools for managing educational content and learning trajectories. The process of convergence is defined as synchronization and coordination of electronic educational resources, educational programs and skill levels of specialists. The process is presented within the framework of interaction and 
lifecycle model synchronization for components of the information learning environment. The environment ensures the convergence of new educational models (electronic, mobile, cloud, mixed, ubiquitous) on the basis of a unified educational management system. The system includes the Alfresco educational content management subsystem, the Moodle learning management subsystem, the learning material presentation subsystem, the knowledge assessment subsystem, the learning activity management subsystem, the requirements of education standards and employers' analysis subsystem.

Next elected article titled "Automated system for evaluating higher education programs" introduced a multi-process program evaluation that could be enhanced using an automated system that streamlines the different processes for education institutes. Authors proposed a software tool design called Automated Program Review Management System (APRMS) to support and manage the program review process. The system has been evaluated using both quantitative and qualitative criteria. Particularly, a case study was depicted that used real data, collected from a program review process in United Arab Emirates University.

Next article titled "A Design-based Research Approach for Developing DataFocussed Business Curricula" develops an opportunity to rethink how institutions can develop innovative data-focussed education programmes, addressing both modern industry and community demands. As both academia and industry strive to integrate applied learning, transferable and enterprise skills into business and sciences, this paper proposes a design-based research approach (DBR) for designing such a new interdisciplinary data science teaching curriculum as a foundation to deliver business undergraduate degrees in business data science. Adopting a design science method (e.g. Miah and Genemo 2016; Miah and Gammack 2014), the proposed approach illustrated effective utilities for conceptualising and evaluating a fully functional new bachelor of business data science. The findings suggested that proposed DBR ensures the design of an innovative data science degree that may meet growing industry and interdisciplinary demands. Authors concluded by discussing overall feasibility of the proposal in the Australian higher education sector, particularly for the case context of an Australian University.

Next article titled "Deciphering the Attributes of Student Retention in Massive Open Online Courses using Data Mining Techniques" aimed at a massive outreach and open access education, Massive Open Online Courses (MOOC) have evolved incredibly engaging millions of learners' over the years. These courses provide an opportunity for learning analytics with respect to the diversity in learning activity. In spite of its growth, high dropout rate of the learners', it is examined to be a paramount factor that may obstruct the development of the e-learning platforms. Fabricating on the existing efforts of retaining learners' engagement prior to learning, the study explores to decipher the attributes of student retention in e- learning. The study proposed a clear rationale of significant attributes using classification algorithms (Decision Tree) in order to improve course design and delivery for different MOOC providers and learners. Using the three MOOC datasets, this research analysed the approach and results of applying the data mining techniques to online learners', based on their in-course behaviour. Finally, authors predicted the attributes that lead to minimise attrition rate and analyse the different cohort behaviour and its impacts for dropouts using data mining technique.

Next article titled "Is Moodle or WhatsApp the preferred e-learning platform at a South African university? First-year students' experiences" revealed that a personal e- 
learning platform which was neglected previously could be used to improve e-learning process and practices in the present era. The study also revealed that while students only had the option of using the Moodle e-learning platform, they preferred to use their more familiar informal e-learning platform such as WhatsApp. The study concluded that without considering the use of a personal e-learning platform that blends both Moodle and WhatsApp, the problem might be further escalated.

Finally, the article titled "A Literature Review: Efficacy of Online Learning Courses for Higher Education Institution using Meta-Analysis" described a literature review through meta-analysis as the method of research concerning the use of ADDIE (Analysis, Design, Development, Implementation and Evaluation) framework. Authors focused on for designing and developing instructional materials that can provide wider access to quality higher education. This framework represented a descriptive guideline for building effective training and performance support tools in five phases, as follows: 1.) Analysis, 2.) Design, 3.) Development, 4.) Implementation, and 5.) Evaluation. Researchers highlighted the importance of instructional design and the active role of institutions play in providing support structures for educators and students.

\section{References}

Asamoah, D. A., Sharda, R., Zadeh, A. H., \& Kalgotra, P. (2017). Preparing a data scientist: A pedagogic experience in designing a big data analytics course. Decision Sciences Journal of Innovative Education, 15(2), 161-190.

Baesens, B., Bapna, R., Marsden, J. R., Vanthienen, J., \& Zhao, J. L. (2016). Transforming issues of big data and analytics in networked business. MIS Quarterly, 40(4), 807-818.

Bocevska, A., Savoska, S., Risteveski, B., and Blazeska-Tabakovska, N., (2018). Analysis of Accessibility of the e-Learning Platforms According to the WCAG 2.0 Standard Compliance, In the proceedings of International conference on Applied Internet and Information Technologies, URL: http://eprints.uklo.edu. mk/1486/. Accessed on 20 Dec 2019.

Cech, E. A. (2013). Culture of disengagement in engineering education? Science, Technology \& Human Values, 39(1), 42-72.

Emelyanova, N. and Voronina, E. (2014). Introducing a Learning Management System at a Russian University: Students' and Teachers' Perceptions, URL: http://www.irrodl.org/index. php/irrodl/article/view/1701/2801. Accessed on 20 Dec 2019.

Gandomi, A., \& Haider, M. (2015). Beyond the hype: Big data concepts, methods, and analytics. International Journal of Information Management, 35, 137-144.

Genemo, H., Miah, S.J., and McAndrew, A. (2016). A design science research methodology for developing a computer-aided assessment approach using method marking concept Education and Information Technologies, 21(6), 1769-1784

McAfee, A., Brynjolfsson, E., Davenport, T. H., Patil, D. J., \& Barton, D. (2012). Big data. The management revolution. Harvard Business Review, 90(10), 61-67.

Miah, S. J., \& Gammack, J. (2014). Ensemble artifact Design for Context Sensitive Decision Support. Australasian Journal of Information Systems, 18(2), 5-20.

Miah, S. J., \& Genemo, H. (2016). A design science research methodology for expert systems development. Australasian Journal of Information Systems, 20, 1-29.

Miah, S. J., Kerr, D., Gammack, J., \& Cowan, T. (2008). A generic design environment for the rural industry knowledge acquisition. Knowledge-Based Systems, 21(8), 892-899.

Miah, S. J., Vu, H. Q., Gammack, J., \& McGrath, G. M. (2017). A big-data analytics method for tourist behaviour analysis. Information and Management, 54, 771-785.

Miah, S. J., Gammack, J., \& McKay, J. (2019). A Metadesign theory for Tailorable decision support. Journal of the Association for Information Systems, 20(5), 570-603.

Miah, S. J., Vu, H. Q., \& Gammack, J. (2019a). A big-data analytics method for capturing visitor activities and flows: The case of an island country. Information Technology and Management, 20(4), 203-221. 
Miah, S. J., Vu, H. Q., \& Gammack, J. (2019b). A location analytics method for the utilisation of Geotagged photos in travel marketing decision-making. Journal of Information \& Knowledge Management, 18(01), 1950004.

Miah, S. J., Solomonides, I., \& Gammack, J. (2020). A design-based research approach for developing datafocussed business curricula. Education and Information Technologies, 25, 553-581.

Newell S., and Marabelli, M. (2014). The crowd and sensors era: Opportunities and challenges for individuals, organizations, society, and researchers, In Proceedings of 35th ICIS, December 14-17, Auckland, NZ.

Pardos, Z. A. (2017). Big data in education and the models that love them. Current Opinion in Behavioral Sciences, 18, 107-113.

Singh, H., \& Miah, S. J. (2019). Design of a mobile-based learning management system for incorporating employment demands: Case context of an Australian University. Education and Information Technologies, 24, 995-1014.

Stern, D. M., \& Willits, M. D. (2011). Social media killed the LMS: Re-imagining the traditional learning management system in the age of blogs and online social networks. Cutting-edge Technologies in Higher Education, 1, 347-373.

Tenney, M. \& Sieber, R. (2016). Data-Driven Participation: Algorithms, Cities, Citizens, and Corporate Control. Urban Planning, 1(2), 101-113.

Valsamidis, S., Kazanidis, I., Kontogiannis, S., \& Karakos, A. (2012). An approach for LMS assessment. International Journal Technology Enhanced Learning, 4(3/4), 265-283.

Wang, L., Sy, A., Liu, L., and Piech, C. (2017). Learning to represent student knowledge on programming exercises using deep learning. In Proceedings of the 10th International Conference on Educational Data Mining; Wuhan, China, 324-329.

Zanjani, N., Edwards, S. L., Nykvist, S., \& Geva, S. (2017). The important elements of LMS design that affect user engagement with e-learning tools within LMSs in the higher education sector. Australasian Journal of Educational Technology, 33(1), 19-31.

Publisher's note Springer Nature remains neutral with regard to jurisdictional claims in published maps and institutional affiliations. 